\title{
MOVIMENTO PENDULAR NA REGIÃO METROPOLITANA DO CARIRI (RMC)
}

Sessão Temática: Migração interna e pendularidade

João Gomes da Silva

Mestrando em Demografia pela Universidade Federal do Rio Grande do Norte (UFRN), Bolsista da Coordenação de Aperfeiçoamento de Pessoal de Nível Superior (CAPES) e Pesquisador do Observatório das Migrações no Estado do Ceará (OMEC-CNPq)

Silvana Nunes de Queiroz

Professora Adjunta do Departamento de Economia da Universidade Regional do Cariri (URCA) e Coordenadora do Observatório das Migrações no Estado do Ceará (OMEC-CNPq)

Raíssa Marques Sampaio Sidrim Mestranda em Demografia pela Universidade Federal do Rio Grande do Norte (UFRN), Bolsista da Coordenação de Aperfeiçoamento de Pessoal de Nível Superior (CAPES) e Pesquisadora do Observatório das Migrações no Estado do Ceará (OMEC-CNPq)

\section{RESUMO}

Pesquisas sobre deslocamentos cotidianos por motivo de trabalho e/ou estudo em algumas áreas da região Nordeste são incipientes na literatura brasileira. Sendo assim, este estudo tem como objetivo principal analisar e comparar a mobilidade pendular entre os nove municípios que compõe a Região Metropolitana do Cariri (RMC), dado que a mesma foi criada oficialmente pelo governo do estado em 2009. Para tanto, os microdados da amostra do Censo Demográfico 2010 são a principal fonte de informações. Os principais resultados mostram que na RMC, os municípios de Juazeiro do Norte, Crato e Barbalha, conhecidos como o triângulo CRAJUBAR, são responsáveis pelos maiores volumes de deslocamentos diários nesse espaço metropolitano localizado no Sul Cearense. Ademais, Juazeiro do Norte e Barbalha recebem diariamente mais pessoas por motivo de trabalho, dado a centralidade de empreendimentos econômicos e empresariais em tais municípios, mostrando a dependência dos demais integrantes da RMC. Por outro lado, Crato se destaca na atratividade diária por motivo de estudo que suplanta o motivo trabalho. Tal dinâmica ratifica a sua vocação histórica de "celeiro" da Educação e Cultura no Sul do Ceará.

Palavras-Chave: Mobilidade; Pendularidade; RMC.

\section{INTRODUÇÃO}

A partir dos anos 1980, com a desconcentração da atividade econômica e da população dos grandes centros urbanos, estudos sobre o movimento pendular, paulatinamente, ganha espaço na literatura brasileira. Vale salientar que o movimento pendular é entendido como o deslocamento diário entre municípios diferentes, motivado por razões de estudo e/ou trabalho, que propiciam um elo entre as relações sociais em diferentes áreas, mediante mudanças no mercado de trabalho, habitacional e urbanização (OLIVEIRA, 2006).

No que concerne ao intenso fluxo diário nas principais Regiões Metropolitanas do Brasil, notadamente no Sudeste, Silva (2012) mostra que a Região Metropolitana de São 
Paulo (RMSP) sempre se caracterizou como área de mobilidade pendular, por ser um local de atratividade populacional, principalmente de migrantes de longas distâncias (interestaduais), que ao chegarem na RMSP escolhiam residir na periferia por questões de moradia mais acessível, tendo que se deslocar até a metrópole/capital para realizar as suas atividades diárias de trabalho e/ou estudo.

No tocante as regiões metropolitanas do Nordeste, não há tantas pesquisas que abordem essa temática. O estudo de Brito e Ramalho (2014) analisa o movimento pendular entre os quatorzes municípios da Região Metropolitana de Recife (RMR), que revela acentuado volume de pessoas que se deslocam por motivo de trabalho e/ou estudo em tal metrópole. Por sua vez, Gonçalves (2011) salienta que a pendularidade na Região Metropolitana de Fortaleza (RMF) tem intensificação a partir do distanciamento entre os locais de residência e onde os indivíduos realizam suas atividades cotidianas.

Em tal contexto, Silva (2016) complementa os estudos de Brito e Ramalho (2014) e Gonçalves (2011), ao comparar as características da mobilidade cotidiana nas três RM's do Nordeste, estendendo tal análise para a Região Metropolitana de Salvador (RMS), dado que ainda não se conhece estudos sobre pendularidade para essa metrópole. Com isso, o autor conclui que a RMR apresenta um volume três vezes maior de pessoas circulando diariamente no seu espaço metropolitano quando comparado a RMF, que apresenta o segundo maior fluxo, seguido da RMS.

Portanto, o principal objetivo deste artigo é analisar e comparar a mobilidade pendular entre os nove municípios que compõe a Região Metropolitana do Cariri (RMC), dado que até o momento não se conhece estudos sobre essa área metropolitana, localizada no Sul cearense, composta pelos municípios de Barbalha, Caririaçu, Crato, Farias Brito, Jardim, Juazeiro do Norte, Missão Velha, Nova Olinda e Santana do Cariri. Os mesmos estão distribuídos numa área de $5.412,3 \mathrm{Km}^{2}$ e, em 2010, conta com um contingente populacional de 564.478 habitantes (IBGE, 2011).

Além desta introdução, a segunda seção descreve brevemente estudos sobre o movimento pendular no Brasil. A terceira aborda questões relacionadas a institucionalização, características populacionais e econômicas da RMC. A quarta apresenta os procedimentos metodológicos utilizados para mensurar a mobilidade pendular. A quinta analisa a pendularidade entre os municípios da RMC e, por fim, a última seção apresenta as conclusões do estudo.

\section{A PENDULARIDADE NO BRASIL}


Esta seção descreve brevemente estudos sobre a mobilidade pendular no Brasil. Para tanto é preciso destacar que as pesquisas sobre o fluxo entre casa-trabalho e/ou casa-estudo são incipientes na literatura nacional, isto porque, este movimento teve início nas grandes metrópoles do Sudeste do país, notadamente a partir da década de 1980.

Magalhães e D'avila (1996) averiguaram no estudo sobre os fluxos intra-urbano na Região Metropolitana de Belo Horizonte (RMBH), que a reversão das atividades econômicas em termos locacionais propiciou intenso deslocamento populacional para os munícipios nos arredores da metrópole (Belo Horizonte). A elevação dos custos habitacionais nas grandes cidades fez com que tanto indústrias como trabalhadores optassem por residir em locais mais afastados. Assim, os autores concluem que a mobilidade populacional está influenciada pela locomoção do capital, a qual condiciona seletividade nos padrões do espaço metropolitano.

Nesse sentido, Baeninger (2001) aponta para a expansão e a consolidação do espaço urbano paulista que remete a pendularidade:

O movimento pendular constitui, hoje, um dos mais importantes fenômenos da região; esse tipo de movimento também se diferencia quando consideradas as características dos municípios no contexto econômico metropolitano e a inserção da população ocupada neles residente. A integração do mercado de trabalho metropolitano propicia esse fenômeno que, associado à necessidade de buscar locais de moradia mais baratos, marca o cotidiano de grande número de trabalhadores [...], fatores que impulsionaram a formação desse espaço urbano-metropolitano e contribuíram para relativa desconcentração populacional do município-sede em relação aos municípios vizinhos (BAENINGER, 2001, p. 344).

Quanto a pendularidade na Região Metropolitana do Rio de Janeiro (RMRJ), esta apresenta um processo diferente das demais, que é a periferização da metrópole, isto é, o fluxo de pessoas que saem da periferia para residir em grandes centros. No entanto, também há fatores comuns, como a presença de condomínios fechados em locais mais afastados dos centros metropolitanos, condicionando a expansão da periferia. Ademais, na RMRJ também se destaca a mobilidade populacional entre periferia-periferia, mostrando que o principal condicionante da mudança de residência está associado à questão dos rendimentos e consequentemente às dificuldades de continuar morando nos grandes centros. Com isso, cada vez mais, os municípios periféricos apresentam um mercado imobiliário e ocupacional dinâmico e praticamente independente (JARDIM, 2001).

Aranha (2005) aponta que o principal motivo que influencia o movimento pendular entre os municípios é o trabalho. Os deslocamentos pendulares acontecem de forma generalizada entre os municípios da RMSP, onde locais mais atrativos também se tornam ponto de partida para outros indivíduos que se deslocam em direção a outro município. No entanto, conclui que em ambos os locais, sejam municípios industriais ou dormitórios, possuem características de "emitir" e de "receber" pessoas de outras áreas. 
Brito e Souza (2005) mostram que a pendularidade caracteriza-se como o deslocamento intrametropolitano, influenciado pela expansão dos espaços urbanos, o qual proporciona distanciamento entre os locais de moradia e os lugares que as pessoas realizam as atividades (trabalho e/ou estudo). No entanto, os indivíduos com poder aquisitivo mais alto decidem morar em lugares distantes dos grandes centros metropolitanos, desde que as externalidades positivas equilibrem os custos adicionais nas áreas denominadas de periferia. No que se refere a população mais pobre, estas saem em busca de moradia no entorno das metrópoles devido à restrição imobiliária e/ou valor do aluguel/habitação.

Jardim e Ervatti (2006) constatam que a mobilidade pendular está entrelaçada com deslocamentos residenciais, dado a centralidade do mercado de trabalho. Embora esse não seja o único motivo, há também outras ações que influenciam na mudança de residência para localidades a margem da metrópole. Portanto, esses movimentos baseiam-se prioritariamente nas condições de vida das pessoas, onde é preferível mudar de residência para a periferia do que viver na metrópole em condições sub-humanas.

Diante disso, tem-se que a mobilidade diária se deve as diferenças socioeconômicas da sociedade, realizadas por populações de classes distintas, sendo que cada localidade possui uma característica que condiciona uma seletividade para tais deslocamentos. Ademais, no tocante ao rendimento dos indivíduos em condições de trabalho, aqueles que praticam a pendularidade, em geral, possuem maior renda quando comparado aos que não se deslocam para trabalhar em um município diferente da sua residência. Não obstante, a dinâmica intrametropolitana é considerada como o princípio da mobilidade pendular (PESSINI, 2007).

Ojima (2011) destaca que não se pode restringir o movimento pendular apenas as localidades mais desprovidas de serviços ou economicamente fracas, localizadas no entorno dos polos mais desenvolvidos em determinada região, pois a pendularidade não se limita ao contingente mais pobre, mas as mudanças sociais constituídas por uma população com padrões diferentes, que se sente forçada pelas mudanças da estrutura urbana, morarem em localidades distantes dos grandes aglomerados urbanos.

Silva (2012) enfatiza que a pendularidade é o deslocamento que não implica em mudança de residência, mas apenas um percurso frequente entre duas localidades distintas, a de residência para o trabalho e/ou estudo. Ademais, esse movimento diário está relacionado com a expansão de um determinado local, condicionado a centralidade de investimentos e sobretudo a oferta de trabalho. Dessa forma, os deslocamentos temporários se tornam mais intensos a medida em que as distâncias percorridas por estes aumentam, onde o principal local de moradia ainda é no entorno das regiões metropolitanas. 
No que concerne aos estudos sobre mobilidade pendular no Nordeste, Brito e Ramalho (2014) estudaram esse fluxo na Região Metropolitana de Recife (RMR), e mostram expressivo volume de pessoas circulando diariamente entre os seus quatorzes municípios. Ademais, conforme os autores, a maior parcela da população que se desloca para outros municípios, são "migrantes típicos" (indivíduo com experiência de migração), sendo mais propensos a assumir postos de trabalhos em locais distantes de onde residem.

Gonçalves (2011) fez uma pesquisa também para o Nordeste, especificamente para a Região Metropolitana de Fortaleza (RMF) e conclui que mediante as desagregações econômicas, antes concentradas especificamente na capital, houve maior integração entre a metrópole (Fortaleza) com os municípios periféricos. Diante disso, a pendularidade entre os municípios da RMF têm se tornado uma dinâmica dissociada entre o local de residência e o de suas atividades cotidianas, trabalho e/ou estudo, onde os indivíduos são motivados a se deslocarem para locais mais dinamizados do que o local em que residem.

Por sua vez, Silva (2016) analisa as características da mobilidade pendular nas Regiões Metropolitanas de Fortaleza, Recife e Salvador, e constata que esse fluxo está relacionado com as particularidades de cada município, no que diz respeito a absorção da mão de obra, bem como pela oferta de um sistema educacional capaz de atender a demanda da população, concentrados notadamente nos municípios/capitais de Fortaleza, Recife e Salvador.

\section{INSTITUCIONALIZAÇÃO E CARACTERÍSTICAS POPULACIONAIS E ECONÔMICAS DA RMC}

Esta seção aborda como se deu o processo de institucionalização da RMC, além de apresentar algumas características populacionais e econômicas dessa metrópole.

A Região Metropolitana do Cariri (RMC) foi decretada oficialmente em 29 de julho de 2009, pela Lei complementar estadual n 78/2009, Art $1^{\circ}$, regido pelo Art. 43 da Constituição Estadual. A sua criação foi em prol de favorecer e organizar a integração entre os nove municípios que compõe essa área, propiciando uma reconfiguração através de políticas públicas para o interesse de todos (CEARÁ, 2009).

A Figura 1 mostra a localização geográfica da RMC no estado do Ceará, que está há $550 \mathrm{Km}$ da capital cearense (SILVA; QUEIROZ, 2016) e é composta por nove municípios: Barbalha, Caririaçu, Crato, Farias Brito, Jardim, Juazeiro do Norte, Nova Olinda e Santana do Cariri. Ademais, a Região Metropolitana do Cariri (RMC) está numa área de 5.412,3 Km², sendo que a cidade de Crato apresenta a maior extensão territorial desse espaço $(1.157,9$ $\left.\mathrm{Km}^{2}\right)$. 


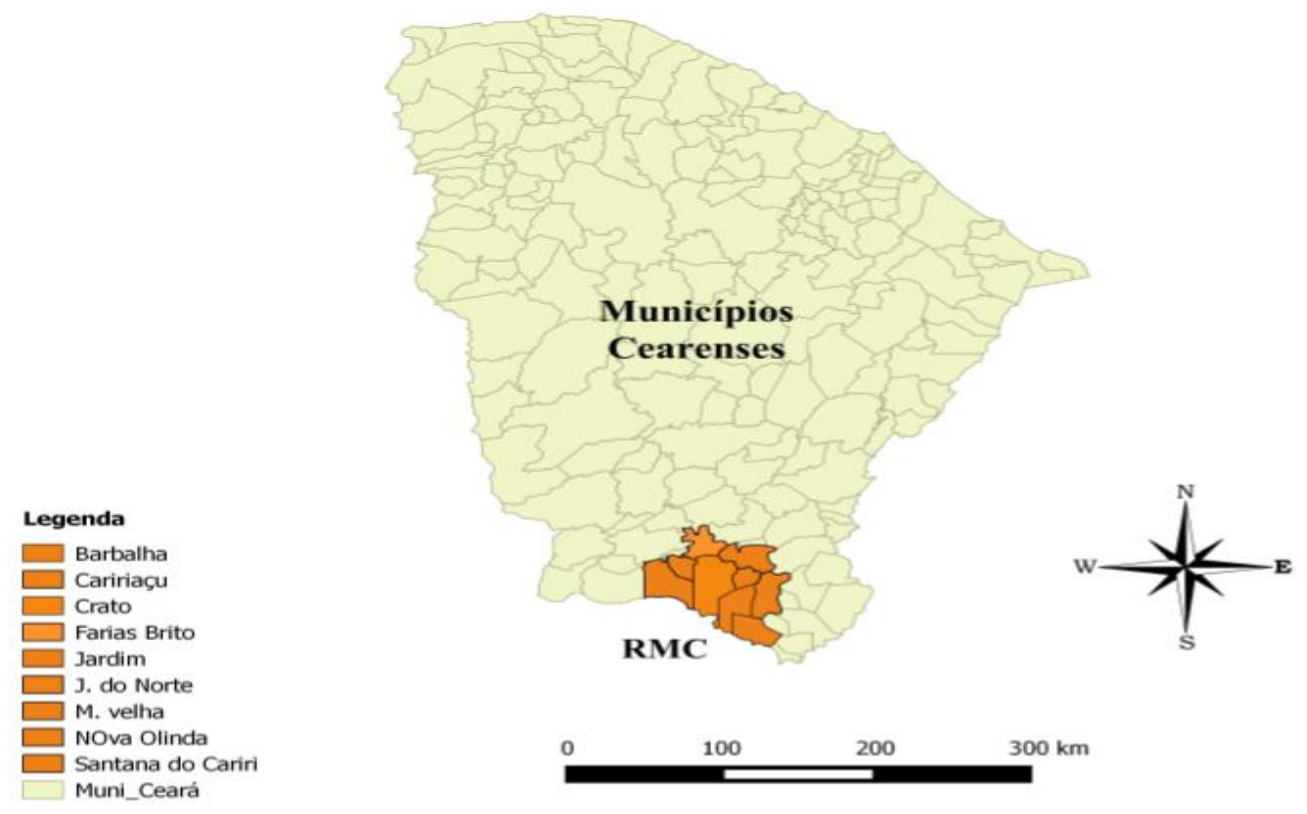

Figura 1 - Localização e divisão política da RMC no Ceará

Fonte: Elaboração própria a partir da Malha Municipal Digital do Brasil (IBGE-2010).

Em 2010 a população da RMC corresponde a 564.478 mil habitantes, dos quais 44,28\% reside somente no município de Juazeiro do Norte. Crato está em segunda posição com 21,51\%, e Nova Olinda aponta a menor concentração populacional dessa metrópole, com somente $2,53 \%$ (Tabela 1 ).

Tabela 1 - População total, urbana e rural dos municípios da Região Metropolitana do Cariri (RMC) - 2010

\begin{tabular}{l|c|c|c|c|c|c|c}
\hline $\begin{array}{c}\text { Municípios da } \\
\text { RMC }\end{array}$ & $\begin{array}{c}\text { População } \\
\text { Total }\end{array}$ & $\boldsymbol{\%}$ & $\begin{array}{c}\text { População } \\
\text { Urbana }\end{array}$ & $\%$ & $\begin{array}{c}\text { População } \\
\text { Rural }\end{array}$ & \% & $\begin{array}{c}\text { Área } \\
\text { Km}^{2}\end{array}$ \\
\hline Barbalha & 55.323 & 9,80 & 38.022 & 68,73 & 17.301 & 31,27 & 569,5 \\
Caririaçu & 26.393 & 4,68 & 14.031 & 53,16 & 12.362 & 46,84 & 623,5 \\
Crato & 121.428 & 21,51 & 100.916 & 83,11 & 20.512 & 16,89 & $1.157,9$ \\
Farias Brito & 19.007 & 3,37 & 8.871 & 46,67 & 10.136 & 53,33 & 503,6 \\
Jardim & 26.688 & 4,73 & 8.994 & 33,70 & 17.694 & 66,30 & 519,1 \\
Juazeiro do Norte & 249.939 & 44,28 & 240.128 & 96,07 & 9.811 & 3,93 & 248,2 \\
Missão Velha & 34.274 & 6,07 & 15.419 & 44,99 & 18.855 & 55,01 & 650,5 \\
Nova Olinda & 14.256 & 2,53 & 9.696 & 68,01 & 4.560 & 31,99 & 284,4 \\
Santana do Cariri & 17.170 & 3,04 & 8.822 & 51,38 & 8.348 & 48,62 & 855,6 \\
\hline RMC & $\mathbf{5 6 4 . 4 7 8}$ & $\mathbf{1 0 0}$ & $\mathbf{4 4 4 . 8 9 9}$ & $\mathbf{7 8 , 8 2}$ & $\mathbf{1 1 9 . 5 7 9}$ & $\mathbf{2 1 , 1 8}$ & $\mathbf{5 . 4 1 2 , 3}$ \\
\hline
\end{tabular}

Fonte: Microdado da amostra do Censo Demográfico 2010 (IBGE). Elaborado pelo Observatório das Migrações no Estado do Ceará (OMEC-CNPq-URCA).

O baixo contingente populacional de Nova Olinda se justifica pela escassez de oportunidades de emprego, estudo e lazer, em parte, justificando as suas perdas populacionais 
ao longo dos anos, notadamente para os municípios do CRAJUBAR (Crato, Juazeiro e Barbalha) (SILVA; QUEIROZ, 2016).

Com relação a população urbana da RMC, esta apresenta um volume de 444.899 pessoas ou 78,82\% da população total. Em nível municipal, Juazeiro do Norte se destaca com 96,07\% residindo em área urbana, acompanhado por Crato (83,11\%), Barbalha $(68,73 \%)$ e Nova Olinda $(68,01 \%)$. Em parte, a presença de diversos segmentos comerciais, industriais, educacionais e de lazer, propiciam o aumento da ocupação urbana nesses espaços, fazendo com que haja uma desconcentração populacional/habitacional nos municípios do triângulo CRAJUBAR (Crato, Juazeiro do Norte e Barbalha), que motiva a mobilidade diária entre esses municípios.

No tocante a população residente na zona rural, essa corresponde a um montante de 119.579 pessoas ou 21,18\%, com destaque para Jardim (66,3\%), Missão Velha $(55,01 \%)$ e Faria Brito (53,33\%), que apresentam mais da metade da população residindo nessa área.

Em termos econômicos, a Tabela 2 mostra que o PIB per capita dos nove municípios que compõem a RMC passou de $\mathrm{R} \$ 2.482,00$ em 2002, para $\mathrm{R} \$ 6.772,00$ em 2010. Apesar de nos dois períodos exibir valor inferior a média do estado, que foi de $\mathrm{R} \$ 3.735,00 \mathrm{em} 2002$ e R\$ 9.217,00 em 2010, a RMC (272,84\%) apresenta variação superior a do Ceará $(246,77 \%)$, no referido intervalo.

Tabela 2 - PIB per capita dos municípios da Região Metropolitana do Cariri (RMC) 2002/2010

\begin{tabular}{l|cc|c}
\hline \multirow{2}{*}{ Municípios } & \multicolumn{2}{|c|}{ PIB Per capita (R\$) } & \multirow{2}{*}{ Variação (\%) } \\
\cline { 2 - 3 } & $\mathbf{2 0 0 2}$ & $\mathbf{2 0 1 0}$ & 312,02 \\
Barbalha & 2.630 & 8.206 & 261,85 \\
Caririaçu & 1.376 & 3.603 & 238,17 \\
Crato & 2.926 & 6.969 & 266,17 \\
Farias Brito & 1.463 & 3.894 & 271,82 \\
Jardim & 1.416 & 3.849 & 257,88 \\
Juazeiro do Norte & 3.041 & 7.842 & 280,61 \\
Missão Velha & 1.578 & 4.428 & 236,59 \\
Nova Olinda & 1.932 & 4.571 & 280,97 \\
Santana do Cariri & 1.524 & 4.282 & $\mathbf{2 7 2 , 8 4}$ \\
\hline RMC & $\mathbf{2 . 4 8 2}$ & $\mathbf{6 . 7 7 2}$ & $\mathbf{2 4 6 , 7 7}$ \\
\hline Ceará & $\mathbf{3 . 7 3 5}$ & $\mathbf{9 . 2 1 7}$ & \\
\hline RMC/CE & $\mathbf{6 6 , 4 4}$ & $\mathbf{7 3 , 4 7}$ & \\
\hline
\end{tabular}

Fonte: IPECE e IBGE (2012).

Em relação aos municípios, Barbalha apresenta maior variação $(312,02 \%)$ nesse intervalo, inclusive maior que o da RMC e o do Ceará, com crescimento de R\$2.630,00 
(2002) para $\mathrm{R} \$ 8.206,00$ (2010), alcançando o maior PIB per capita da metrópole caririense no último ano em estudo (Tabela 2).

Além de Barbalha, nos dois anos em análise, os únicos municípios que obtiveram PIB per capita superior ao da RMC foram Juazeiro do Norte e Crato, mas inferior a média cearense. Em 2002, com PIB de R\$3.041,00, Juazeiro do Norte se destaca como o mais expressivo da região metropolitana. Em 2010, ficou atrás de Barbalha ( $\mathrm{R} \$ 8.206,00)$, ao exibir PIB per capita de R $\$ 7.842,00$. Já Crato passou de um PIB per capita de R $\$ 2.926,00$ no primeiro ano (segundo maior) para $\mathrm{R} \$ 6.969,00$ (terceiro maior) no último. É importante destacar que, em ambos os anos em estudo, nenhuma cidade da Região Metropolitana do Cariri obteve PIB per capita superior do estado (Tabela 2).

Através da Tabela 3 podemos analisar a distribuição setorial da atividade econômica de cada município da RMC e o PIB em valores (R\$). Em 2002, esta área metropolitana contribuiu com 4,46\% ( $\mathrm{R} \$ 1.289 .748)$ do valor do PIB cearense ( $\mathrm{R} \$ 28.896 .188$ ) e aumenta para $4,91 \%$ no ano de 2010.

Tabela 3 - Distribuição setorial da atividade econômica e PIB em R\$ (mil), segundo os municípios da Região Metropolitana do Cariri (RMC) e Ceará - 2002/2010 (\%)

\begin{tabular}{|c|c|c|c|c|c|}
\hline \multirow{3}{*}{ Municípios } & \multicolumn{5}{|c|}{2002} \\
\hline & \multicolumn{3}{|c|}{ Composição Setorial (\%) } & \multicolumn{2}{|c|}{ PIB em R\$ mil } \\
\hline & Agropecuária & Indústria & Serviços & Abs. & $(\%)$ \\
\hline Barbalha & 6,71 & 31,27 & 62,02 & 140.808 & 10,92 \\
\hline Caririaçu & 20,86 & 8,28 & 70,86 & 35.783 & 2,77 \\
\hline Crato & 3,45 & 19,46 & 77,08 & 337.096 & 26,14 \\
\hline Farias Brito & 14,37 & 10,11 & 75,52 & 29.808 & 2,31 \\
\hline Jardim & 18,49 & 8,13 & 73,38 & 36.065 & 2,80 \\
\hline J. do Norte & 0,71 & 19,14 & 80,14 & 610.318 & 47,32 \\
\hline Missão Velha & 21,72 & 9,19 & 69,09 & 49.840 & 3,86 \\
\hline Nova Olinda & 11,58 & 24,34 & 64,08 & 23.589 & 1,83 \\
\hline Santana do Cariri & 21,84 & 12,88 & 65,28 & 26.441 & 2,05 \\
\hline RMC & 5,1 & 19,2 & 75,69 & 1.289 .748 & $\mathbf{1 0 0 , 0 0}$ \\
\hline Ceará & 7,28 & 24,53 & 68,19 & 28.896.188 & - \\
\hline RMC/CE & & - & - & 4,46 & - \\
\hline \multirow{3}{*}{ Municípios } & \multicolumn{5}{|c|}{2010} \\
\hline & \multicolumn{3}{|c|}{ Composição Setorial $(\%)$} & \multicolumn{2}{|c|}{ PIB em R\$ mil } \\
\hline & Agropecuária & Indústria & Serviços & Abs. & $(\%)$ \\
\hline Barbalha & 3,06 & 32,33 & 64,61 & 454.410 & 11,89 \\
\hline Caririaçu & 8,05 & 12,74 & 79,21 & 95.077 & 2,49 \\
\hline Crato & 2,86 & 16,38 & 80,76 & 846.429 & 22,14 \\
\hline Farias Brito & 7,13 & 11,38 & 81,49 & 74.022 & 1,94 \\
\hline Jardim & 11,1 & 9,12 & 79,78 & 102.759 & 2,69 \\
\hline J. do Norte & 0,33 & 19,05 & 80,62 & 1.959 .969 & 51,27 \\
\hline Missão Velha & 11,84 & 18,51 & 69,66 & 151.710 & 3,97 \\
\hline
\end{tabular}




\begin{tabular}{lccccc} 
Nova Olinda & 7,37 & 22,96 & 69,67 & 65.168 & 1,70 \\
Santana do Cariri & 18,5 & 11,97 & 69,53 & 73.575 & 1,92 \\
\hline RMC & $\mathbf{2 , 8 4}$ & $\mathbf{1 9 , 3 3}$ & $\mathbf{7 7 , 8 3}$ & $\mathbf{3 . 8 2 3 . 1 1 9}$ & $\mathbf{1 0 0 , 0 0}$ \\
\hline Ceará & $\mathbf{4 , 1 6}$ & $\mathbf{2 3 , 7 1}$ & $\mathbf{7 2 , 1 3}$ & $\mathbf{7 7 . 8 6 5 . 4 1 5}$ & - \\
\hline RMC/CE & & - & - & $\mathbf{4 , 9 1}$ & - \\
\hline
\end{tabular}

Fonte: IPECE e IBGE (2012).

No que se refere ao PIB percentual dos municípios da RMC, constata-se através da Tabela 3, que Juazeiro do Norte, sozinho, detém pouco mais da metade (51,27\%) do PIB da metrópole em 2010. Ao se tratar dos três principais municípios metropolitanos, entre $2002 \mathrm{e}$ 2010, houve aumento da participação relativa do PIB de Juazeiro do Norte (crescimento de $3,95 \%$ ) e de Barbalha (aumento de 1,06\%), e somente o Crato apresentou decrescimento (perda de 4\%).

Em relação aos setores, a RMC segue a tendência do estado, isto porque, nos dois anos em estudo, o setor de serviços representa a maior participação (75,68\% em 2002 e 77,83 em 2010), seguido da indústria (19,20\% em 2002 e 19,33\% em 2010) e, por último, o setor agropecuário (5,10\% em 2002 e 2,84\% em 2010) (Tabela 3).

Em nível municipal, Barbalha tem o setor de serviços como o mais significativo em sua economia (62,08\%), contudo, o mais baixo dentre os municípios da RMC. Entretanto, o setor industrial exibiu aumento, ao passar de $31,27 \%$ para $32,33 \%$, entre 2002/2010, se destacando como a maior participação relativa de toda a RMC. O único setor que teve descenso foi o agropecuário, de 6,71\% para 3,06\%, entre 200/2010 (Tabela 3).

No tocante a Juazeiro do Norte, de um período para o outro houve pouca alteração no que se refere a participação nos setores de atividade. Em 2010, sua economia era composta sobretudo pelos setores de serviços $(80,62 \%)$ e indústria $(19,05 \%)$, sendo que o setor agropecuário representava somente $0,71 \%$, o nível mais baixo de todos os municípios da RMC, resultado explicado, em parte, por este município ser urbano em quase sua totalidade $(96,07 \%)$ (Tabelas 1 e 3$)$.

Crato, o terceiro município mais relevante da economia da RMC, em 2010, obteve incremento no setor de serviços de $77,08 \%$ para $80,76 \%$, entre $2002 / 2010$, superado somente por Farias Brito $(81,49 \%)$. Em relação ao setor industrial, houve decrescimento de $19,46 \%$ para 16,38\%, no referido intervalo. O mesmo aconteceu com o setor agropecuário, ao passar de $3,45 \%$ para $2,86 \%$ (Tabela 3 ).

Quanto aos demais municípios, em 2010, Farias Brito, Jardim e Caririaçu se destacavam nos serviços $(81,49 \%, 79,78 \%$ e 79,21\%, respectivamente). Nova Olinda $(22,96 \%)$ e Missão Velha $(18,51 \%)$ com relação a indústria. E na agropecuária, Santana do Cariri (18,50\%) e Missão Velha (11,84\%) (Tabela 3). 
É preciso destacar que em anos recentes, na Região Metropolitana do Cariri, a indústria calçadista ganha destaque. Em 1995, com o "Programa de Promoção Industrial e Atração de Investimentos", que tinha como objetivo desenvolver uma estrutura que dava oportunidade de investimentos industriais por meio de incentivos financeiros e fiscais, auxílio tecnológico, mercado e infraestrutura, para que empresários locais, nacionais ou estrangeiros empreendessem investimentos no estado, foram empregados $R \$$ 203.447.288,39 na região, divididos em 60 unidades industriais de setores diversos. Contudo, o setor calçadista recebeu uma parcela de $\mathrm{R} \$ 75.840 .146,00$, isto é, $37 \%$ do total (BESERRA, 2007; CEARÁ, 1995).

Além disso, entre 2004 e 2008, as prefeituras de Barbalha, Crato e Juazeiro do Norte criaram as Secretarias de Desenvolvimento Econômico, Comércio e Indústria, as quais faziam negociações de terrenos, providenciavam infraestrutura e forneceram incentivos fiscais, como isenção de impostos (BESERRA, 2007).

A RMC, principalmente os municípios do triângulo CRAJUBAR (Crato, Juazeiro e Barbalha), contam com um setor de serviços e comércio diversificado, principalmente motivado pelos eventos de cunho religioso que acontecem na região e estimulam sua economia (MACAMBIRA, 2008).

Ademais, segundo Oliveira (2014), os investimentos industriais da década de 1990 deram início ao aumento das migrações das cidades de menor porte para Crato, Juazeiro e Barbalha, principais municípios da região. Tal marcha fez com que houvesse dinamização do comércio e serviços, estabelecendo predomínio de atividades terciárias, sendo o comércio varejista, atacadista, serviços médicos e ensino os mais relevantes.

\section{METODOLOGIA}

\subsection{Passos Metodológicos}

Para o alcance do objetivo proposto, os microdados da amostra do Censo Demográfico 2010 foram a principal fonte de informação. No tocante ao recorte geográfico, os nove municípios da RMC são a área de análise desse trabalho. Por sua vez, a seleção das variáveis e o tratamento estatístico das informações foi realizado através do software estatístico SPSS (Statistical Package for the Social Sciense).

\subsection{Definições Adotadas no Estudo}

A mobilidade pendular é entendida como o deslocamento de casa para o trabalho e/ou de casa para o estudo, entre os municípios que formam a RMC.

Abaixo são apresentadas algumas definições adotadas no estudo. 
Mobilidade pendular - indivíduo com dez anos ou mais de idade, que reside em algum município da RMC e trabalha e/ou estuda em outro município da mesma área metropolitana.

Quanto ao cálculo do volume de pessoas que praticam o movimento pendular na RMC, foram elaboradas matrizes para o fluxo entre os nove municípios. As matrizes pendular da referida área são sintetizadas da seguinte forma:

$$
\begin{gathered}
\boldsymbol{A}=\left[\begin{array}{ccc}
\boldsymbol{a} \mathbf{1 1} & \cdots & \boldsymbol{a 1} \mathbf{j} \\
\vdots & \ddots & \vdots \\
\boldsymbol{a j 1} & \cdots & \boldsymbol{a j j}
\end{array}\right] \\
\text { aij = saída do município i para o município j }
\end{gathered}
$$

$\sum_{j=1}^{9} a 1 j$; Total de pessoas que saem do município 1 para os demais municípios da RMC.

$\sum_{i=1}^{9}$ ai1; Total de pessoas que chegam dos demais municípios da RMC para o município 1.

$$
\mathrm{a} 11=\mathrm{a} 22=\mathrm{a} 33=\ldots=\mathrm{ajj}=0
$$

A partir dessas matrizes é possível calcular o movimento pendular entre os nove municípios da RMC e identificar os municípios que mais atraem pessoas, bem como os locais emissores por razões específicas de trabalho e/ou estudo.

\section{MOBILIDADE PENDULAR ENTRE OS MUNICÍPIOS DA RMC}

Esta seção analisa e compara os deslocamentos cotidianos (casa trabalho e casa $\leftrightarrow$ estudo) na Região Metropolitana do Cariri (RMC) por meio de matrizes migratórias, apontando os principais polos atrativos e menos atrativos dessa metrópole. Os movimentos relacionados a dinâmica pendular podem ser vistos através dos resultados da Matriz 1, no qual em 2010, 20.862 pessoas praticam tal deslocamento por questões de trabalho e/ou estudos na RMC.

Em nível municipal, Juazeiro do Norte recebeu 11.754 indivíduos provindos prioritariamente de Crato (5.983) e Barbalha (3.584). No tocante as saídas, Juazeiro do Norte perde diariamente 4.886 pessoas, notadamente para Crato (2.779) e Barbalha (1.539), mas apresenta o maior saldo pendular (6.868) da RMC. Isso ratifica o estudo de Gurgel (2013), ao destacar a concentração populacional nos três municípios do CRAJUBAR, dado que apresentam um caráter socioeconômico e/ou de oportunidades de estudo e trabalho diferenciado dos demais municípios da RMC. 
Matriz 1 - Mobilidade pendular por motivo de trabalho e estudo na RMC - 2010

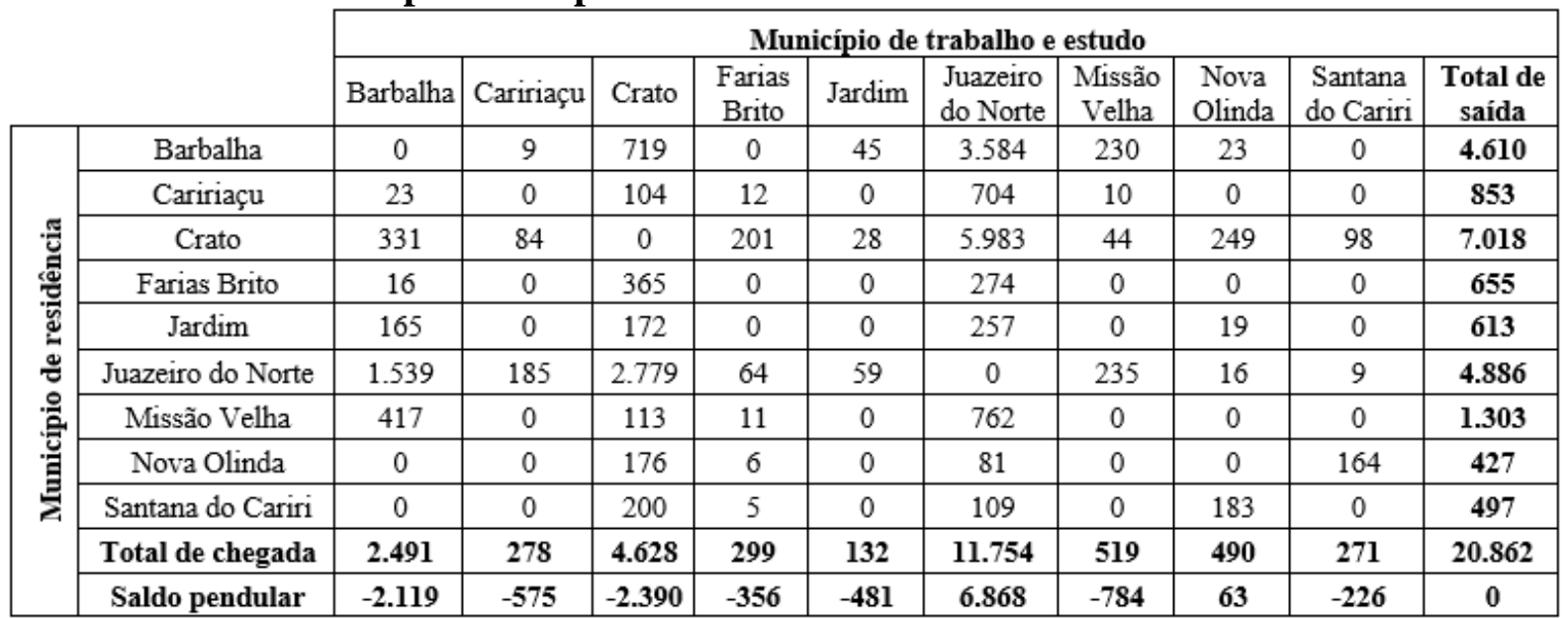

Fonte: Microdados da amostra do Censo Demográfico 2010 (IBGE). Elaborado pelo Observatório das Migrações no Estado do Ceará (OMEC-CNPq-URCA).

Crato se destaca como o segundo município que mais atrai pessoas diariamente, ao receber um volume de 4.628 pessoas, sendo procedentes notadamente dos municípios de Juazeiro do Norte (2.779) e Barbalha (719). Por outro lado, apresenta o maior número de perdas comparadas aos demais municípios da RMC (7.018 indivíduos), dos quais 5.983 se dirigem para Juazeiro do Norte, implicando em um saldo pendular de "perdas" de -2.390 pessoas. Essa dinâmica é explicada pela predominância de recursos investidos notadamente em Juazeiro (51,27\% do PIB da RMC), onde as oportunidades de estudo e, notadamente, de trabalho se destacam quando comparado aos demais municípios que compõe a RMC.

Com relação ao município de Barbalha, esse recebe cotidianamente 2.491 pessoas por motivo de trabalho e estudo, sendo a maioria provinda de Juazeiro do Norte (1.539) e Missão Velha (417), em virtude, em parte, da aproximação geográfica. Quanto as pessoas que deixam essa cidade, do total 4.610 indivíduos, Juazeiro do Norte (3.584) é o principal destino, seguido por Crato (719), ocasionando um saldo 'diário de perda' de -2.119 pessoas. Tais fatos estão relacionados a oferta de trabalho, estudo e diversos empreendimentos públicos que propiciam a atratividade dos municípios vizinhos (Tabela 3 )

Por sua vez, Missão Velha aponta moderado volume de pessoas chegando ao seu território (519), sendo a maioria procedentes de Juazeiro do Norte (235) e Barbalha (230). No que se refere ao fluxo de pessoas que deixam a cidade para trabalhar e/ou estudar em outros municípios da RMC, o volume corresponde a 1.303 pessoas, com destino notadamente para Juazeiro do Norte (762) e Barbalha (417). Portanto, as saídas superam as entradas (saldo pendular de -784), dado que as maiores oportunidades presentes nos municípios receptores, onde há maiores investimentos comparado ao local de origem desses indivíduos (Tabelas 2 e $3)$. 
Ao considerar os deslocamentos somente por questões de trabalho, os resultados da Matriz 2 apresentam que na RMC, 11.247 ou 54\% dos fluxos correspondem apenas ao motivo trabalho. Desse total, Juazeiro do Norte recebe um volume de 6.689 indivíduos, provindos a maioria de Crato (3.659) e Barbalha (2.054). Quanto as saídas, somente 2.641 pessoas 'deixam' Juazeiro, notadamente para Barbalha (1.097) e Crato (1.042), o que lhe proporciona um saldo pendular positivo de 4.048 indivíduos.

Matriz 2 - Mobilidade pendular por motivo de trabalho na RMC - 2010

\begin{tabular}{|c|c|c|c|c|c|c|c|c|c|c|c|}
\hline & \multicolumn{10}{|c|}{ Município de trabalho e estudo } \\
\hline & & Barbalha & Caririaçu & Crato & $\begin{array}{c}\text { Farias } \\
\text { Brito } \\
\end{array}$ & Jardim & $\begin{array}{l}\text { Juazeiro } \\
\text { do Norte }\end{array}$ & $\begin{array}{c}\text { Missão } \\
\text { Velha }\end{array}$ & $\begin{array}{l}\text { Nova } \\
\text { Olinda }\end{array}$ & $\begin{array}{l}\text { Santana } \\
\text { do Cariri }\end{array}$ & $\begin{array}{c}\text { Total de } \\
\text { saída }\end{array}$ \\
\hline \multirow{11}{*}{ 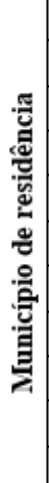 } & Barbalha & 0 & 9 & 243 & 0 & 45 & 2.054 & 206 & 23 & 0 & 2.580 \\
\hline & Caririaçu & 0 & 0 & 36 & 12 & 0 & 436 & 10 & 0 & 0 & 494 \\
\hline & Crato & 198 & 19 & 0 & 183 & 21 & 3.659 & 44 & 73 & 98 & 4.295 \\
\hline & Farias Brito & 16 & 0 & 145 & 0 & 0 & 105 & 0 & 0 & 0 & 266 \\
\hline & Jardim & 66 & 0 & 35 & 0 & 0 & 115 & 0 & 19 & 0 & 235 \\
\hline & Juazeiro do Norte & 1.097 & 142 & 1.042 & 64 & 59 & 0 & 212 & 16 & 9 & 2.641 \\
\hline & Missão Velha & 128 & 0 & 41 & 11 & 0 & 297 & 0 & 0 & 0 & 477 \\
\hline & Nova Olinda & 0 & 0 & 24 & 6 & 0 & 5 & 0 & 0 & 93 & 128 \\
\hline & Santana do Cariri & 0 & 0 & 34 & 5 & 0 & 18 & 0 & 74 & 0 & 131 \\
\hline & Total de chegada & 1.505 & 170 & 1.600 & 281 & 125 & 6.689 & 472 & 205 & 200 & 11.247 \\
\hline & Saldo pendular & -1.075 & -324 & -2.695 & 15 & -110 & 4.048 & -5 & 77 & 69 & 0 \\
\hline
\end{tabular}

Fonte: Microdados da amostra do Censo Demográfico 2010 (IBGE). Elaborado pelo Observatório das Migrações no Estado do Ceará (OMEC-CNPq-URCA).

Portanto, a cidade de Juazeiro do Norte figura como o principal polo atrativo da RMC por questões de trabalho, dado aos variados empreendimentos industriais e comerciais concentrados nesse município (DIAS, 2012). Isso reflete a significante e crescente participação desse município no PIB da RMC.

Por sua vez, Crato se destaca em segundo lugar desse espaço metropolitano, ao receber um volume de 1.600 pessoas por dia por motivo de trabalho, originadas prioritariamente de Juazeiro (1.042). No tocante ao volume de pessoas que 'deixam' cotidianamente essa cidade, tem-se o maior fluxo da RMC, com 4.295 indivíduos, os quais se destinam preferencialmente para Juazeiro (3.659), lhe propiciando um saldo pendular negativo de -2.695 pessoas.

Segundo Queiroz (2003), os municípios do CRAJUBAR, sobretudo Juazeiro do Norte, tem se destacado no cenário econômico cearense devido a concentração econômica e densidade populacional, a partir do aumento da oferta de trabalho, favorecido pelo intenso processo de atração de atividades econômicas.

Barbalha também se destaca no fluxo pendular da RMC, ao atrai 1.505 indivíduos por dia por razões de trabalho, onde a maioria provém de Juazeiro (1.097). Em contrapartida, saem desse município 2.580 indivíduos motivados por trabalho, particularmente para Juazeiro 
(2.054), ocasionando um saldo pendular negativo de -1.075. Tal dinâmica está associada a proximidade geográfica entre esses municípios, bem como pela oferta de emprego e de transportes ligando as mesmas, condicionando um acentuado fluxo pendular (ROCHA; DINIZ, 2015).

Destarte, Missão Velha aponta razoável volume de indivíduos chegando cotidianamente (472) motivados por trabalho, provindos de Juazeiro (212) e Barbalha (202). Quanto as saídas, 477 pessoas deixam esse município diariamente, praticamente o mesmo volume de entradas, onde a maioria também tem como destino Juazeiro (297) e Barbalha (128).

Com relação aos demais municípios (Caririaçu, Farias Brito, Jardim, Nova Olinda e Santana do Cariri) integrantes da RMC, os mesmos apresentam baixo fluxo de entradas por questões de trabalho. Desse modo, evidencia-se a dependência dessas cidades para com o triângulo CRAJUBAR, que concentram os investimentos e/ou PIB, conforme mostrado na Tabela 3, oportunidades de trabalho, estudo, saúde e lazer dessa área metropolitana (QUEIROZ, 2003).

No que concerne a mobilidade pendular apenas por razões de estudo, os dados da Matriz 3 apontam que esse fluxo representa um volume de 9.615 pessoas ou $46 \%$ da pendularidade da RMC. Juazeiro do Norte sobressai como o principal receptor de pessoas motivadas por estudo (5.065), provindos notadamente de Crato (2.324) e Barbalha (1.530). Quanto as saídas, 2.245 indivíduos partem diariamente desse município, dos quais 1.737 se direcionam preferencialmente para o Crato.

Matriz 3 - Mobilidade pendular por motivo de estudo na RMC - 2010

\begin{tabular}{|c|c|c|c|c|c|c|c|c|c|c|c|}
\cline { 3 - 14 } \multicolumn{2}{c|}{} & \multicolumn{9}{c|}{ Município de trabalho estudo } \\
\cline { 2 - 14 } \multicolumn{2}{c|}{} & Barbalha & Caririaçu & Crato & $\begin{array}{c}\text { Farias } \\
\text { Brito }\end{array}$ & Jardim & $\begin{array}{c}\text { Juazeiro } \\
\text { do Norte }\end{array}$ & $\begin{array}{c}\text { Missão } \\
\text { Velha }\end{array}$ & $\begin{array}{c}\text { Nova } \\
\text { Olinda }\end{array}$ & $\begin{array}{c}\text { Santana } \\
\text { do Cariri }\end{array}$ & $\begin{array}{c}\text { Total de } \\
\text { saída }\end{array}$ \\
\hline & Barbalha & 0 & 0 & 476 & 0 & 0 & 1.530 & 24 & 0 & 0 & $\mathbf{2 . 0 3 0}$ \\
\hline Caririaçu & 23 & 0 & 68 & 0 & 0 & 268 & 0 & 0 & 0 & $\mathbf{3 5 9}$ \\
\hline Crato & 133 & 65 & 0 & 18 & 7 & 2.324 & 0 & 176 & 0 & $\mathbf{2 . 7 2 3}$ \\
\hline & Farias Brito & 0 & 0 & 220 & 0 & 0 & 169 & 0 & 0 & 0 & $\mathbf{3 8 9}$ \\
\hline Jardim & 99 & 0 & 137 & 0 & 0 & 142 & 0 & 0 & 0 & $\mathbf{3 7 8}$ \\
\hline
\end{tabular}

Fonte: Microdados da amostra do Censo Demográfico 2010 (IBGE). Elaborado pelo Observatório das Migrações no Estado do Ceará (OMEC-CNPq-URCA).

Dessa maneira, Crato também apresenta expressiva atração por razões de estudo (3.028), a qual excede os seus fluxos motivados por trabalho (1.600). A atratividade do 
município de Crato se deve a presença da Universidade Regional do Cariri (URCA), instituições federais (Instituto Federal de Educação, Ciência e Tecnologia do Ceará - IFCE, e a Universidade Federal do Cariri - UFCA), escolas técnicas em tempo integral, com enorme raio atrativo de estudantes do próprio estado e demais estado vizinho (CEARÁ, 2014).

Nesse contexto, é importante destacar que Barbalha também recebe um moderado fluxo pendular por questões de estudo (986), procedentes de Juazeiro (442) e Missão Velha (289). Em contrapartida, o número de pessoas que saem é bem superior as entradas (2.030), lhe proporcionando um saldo pendular de -1.044. Isso mostra que esse município é dependente de outras cidades, sobretudo de Juazeiro do Norte (1.530) e Crato (476), que concentram maiores oportunidades de estudo na RMC (DIAS, 2012; OLIVEIRA, 2014).

Com relação aos demais municípios da RMC, estes mostram pequeno fluxo de deslocamento por questões de estudo quando comparado ao motivo trabalho. Mas o núcleo metropolitano, precisamente o triângulo CRAJUBAR, com destaque para Juazeiro do Norte, tem a característica de concentrar oportunidades de trabalho, população, renda, Universidades e demais unidades de ensino, que priorizam se instalarem em locais com maior ascensão econômica e concentração populacional.

Portanto, constata-se que os deslocamentos diários na RMC motivados por trabalho e/ou estudo, estão centralizados nos municípios de Juazeiro do Norte, Crato e Barbalha, dado a densidade populacional e a variedades de segmentos econômicos, educacionais e de lazer instalados nesses espaços.

A partir disso, de um lado, percebe-se maior integração entre os demais municípios da RMC e, por outro lado, isso condiciona a dependência dos municípios menores, uma vez que os seus residentes se deslocam para o CRAJUBAR para realizar as suas atividades diárias, implicando no baixo crescimento dos demais municípios.

\section{CONCLUSÃO}

O presente estudo teve como objetivo principal analisar e comparar a mobilidade pendular entre os nove municípios que compõe a Região Metropolitana do Cariri (RMC). Para tanto, foi contextualizado estudos sobre a pendularidade no Brasil, bem como descrito o processo de institucionalização da RMC, características populacionais e econômicas dessa metrópole.

Quanto a formação desse espaço metropolitano localizado no Sul do Ceará, em 2009, foi decretada oficialmente a integração dos nove municípios que compõe a atual Região Metropolitana do Cariri (RMC) que, de um lado, tal reconfiguração espacial propiciou melhor integração entre os municípios menos desenvolvidos com os mais providos de recursos, 
notadamente os que fazem parte do triângulo CRAJUBAR (Crato, Juazeiro do Norte e Barbalha). Por outro lado, a mais estruturada economia da RMC, a tríade CRAJUBAR afeta diretamente o crescimento e desenvolvimento econômico dos municípios vizinhos, que ficam dependentes não somente em relação ao emprego, mas também de serviços, desde os mais básicos como saúde e educação, impossibilitando o seu crescimento.

Nesse sentido, quanto a dinâmica econômica, a RMC, apesar de ter apresentado PIB per capita inferior a média do Ceará, entre 2002 e 2010, exibiu variação superior a média do estado, com participação de 4,91\% no PIB cearense em 2010. Os municípios que apresentam maior participação na economia da área metropolitana são Juazeiro do Norte, Crato e Barbalha, com destaques principalmente nos setores de serviços e indústria. Assim, a mobilidade pendular, conforme apontado por diversos autores, está relacionada com a configuração espacial da atividade econômica e ganha visibilidade nas regiões metropolitanas.

No que concerne aos deslocamentos entre os nove municípios da RMC, Juazeiro do Norte se destaca ao receber diariamente indivíduos motivados por trabalho, sendo provindos notadamente de Crato e Barbalha. Por sua vez, Barbalha aponta com o segundo maior volume de entradas por motivo trabalho, sendo procedente em sua maioria de Juazeiro e Missão Velha, movimentos que se relacionam pela proximidade geográfica, concentração de investimentos econômicos e empresariais, especialmente em Juazeiro.

Com relação a mobilidade pendular motivada por questões de estudo, Juazeiro do Norte novamente é o principal polo de atração da RMC, com indivíduos procedentes em sua maioria de Crato e Barbalha. Mas é importante ressaltar que o município de Crato também apresenta elevado volume de entradas de estudantes, sendo que a atratividade por motivo de estudo supera o de trabalho. Tal fato está relacionado a presença de instituições de ensino superior pública (URCA, UFCA) e privada, além de uma gama de escolas de ensino médio e técnico profissionalizante, sendo um polo educacional de grande importância para o Cariri e Sul Cearense.

Em suma, embora a RMC seja uma área metropolitana localizada no interior do Ceará, as características da mobilidade pendular são semelhantes as demais áreas metropolitanas do país. No entanto, apresenta particularidades, sendo o determinante dos deslocamentos nessa metrópole, a oferta de atividades, estudo e/ou trabalho nos três municípios que formam o triângulo CRAJUBAR (Crato, Juazeiro e Barbalha), ao invés de somente uma localidade.

Todavia, a centralidade econômica, educacional, de infraestrutura e populacional, em três cidades (Crato, Juazeiro e Barbalha) da RMC, faz com que os demais municípios pertencentes a esse espaço metropolitano se tornem ainda mais dependentes dos municípios mais dinamizados. 
Portanto, a decisão dos gestores públicos municipais e estadual, deve passar por aperfeiçoamentos, ao planejar políticas de planejamento urbano, ao alocar da melhor forma os investimentos, para que não haja concentração de oportunidades de emprego e estudo em apenas determinados espaços conurbados como é o triângulo CRAJUBAR.

\section{REFERÊNCIAS}

ARANHA, V. J. Mobilidade Pendular na Metrópole Paulista. São Paulo em Perspectiva, v. 19, p. 96-109, 2005.

BAENINGER, R. A. Região Metropolitana de Campinas: expansão e consolidação do urbano paulista. In: HOGAN, Daniel Joseph. et al. (orgs). Migração e Ambiente nas Aglomerações Urbanas. Campinas: Núcleo de Estudos de População/UNICAMP, p. 321-348, 2001.

BESERRA, F. R. S. Espaço, Indústria e Reestruturação do Capital: A Indústria de Calçados na Região Do Cariri - Ce. Universidade Estadual do Ceará - UECE (Dissertação), 2007.

BRITO, F; SOUZA, J. Expansão Urbana nas Grandes Metrópoles: o significado das migrações intrametropolitanas e da mobilidade pendular na reprodução da pobreza, São Paulo em perspectiva, v. 19, n. 4, p. 48-63, out./dez. 2005.

BRITO, D. J. M; RAMALHO, H. M. B. Mobilidade pendular e histórico de Migração: Evidências para a Região Metropolitana do Recife. In: 42 Encontro Nacional de Economia, 2014, Natal - RN. Mobilidade pendular e histórico de migração: Evidências para a Região Metropolitana do Recife, 2014.

CEARÁ (2009). Lei Complementar N78. In Diário Oficial Do Estado Do Ceará. Promulgada em 26 de junho de 2009. Série 3, Ano I. No 121.

CEARÁ, Câmara dos Deputados (2014), Emenda Constitucional nº19 de 2011, Altera o art. 40 do Ato das Disposições Constitucionais Transitórias para estabelecer a criação da Zona Franca do Semiárido Nordestino. Disponível em <www.camara.gov.br/sileg/integras/1266900.pdf>, acesso em: 20 de dezembro de 2016.

CEARÁ, Governador (Tasso Jereissati). Plano de desenvolvimento sustentável do Ceará, 1995-1998. Fortaleza: SEPLAN, 1995.

DIAS. S. A, Região Caririense: Turismo religioso e manifestações culturais na festa do pau sagrado de Santo Antônio de Barbalha. 2012. F, 156, Dissertação (Mestrado em Geografia), Universidade Estadual do Ceará - UECE, 2012.

GONÇALVES, E. T. Região metropolitana de Fortaleza: o município de Caucaia na dinâmica de integração e mobilidade intrametropolitana, Caminhos de Geografia Uberlândia v. 12, n. 40, p. $144-154$ dez/2011.

GURGEL. C. A. P, Três cidades, uma Região Metropolitana e seus centros: configuração urbana e dinâmica de centralidades do Crajubar-CE, observatóruim, v.5, p.78-102, 2013.

IBGE. Censo Demográfico 2010. Rio de Janeiro, 2011. (Microdados). 
JARDIM, A. P. Mobilidade intrametropolitana: o caso do Rio de Janeiro. Tese (Doutorado em Planejamento Urbano e Regional), Instituto de Pesquisa e Planejamento Urbano e Regional, 266f, Universidade Federal do Rio de Janeiro, Rio de Janeiro, 2001.

MACAMBIRA, J. Mercado de trabalho no Cariri: Uma Análise dos Municípios de Juazeiro do Norte, Crato e Barbalha, 2008. Disponível em:

<http://www.sineidt.org.br/PortalIDT/arquivos/publicacao/Mercado_de_trabalho_do_Cariri.p df $>$. Acesso em: 10 de Fevereiro de 2017.

MAGAlHÃES, D. J. A. V; D'ÁVILA, A. E. C. Migrações dentro da Região

Metropolitana de Belo Horizonte Visando Moradia Próxima ao Local de Trabalho. In: X Encontro Nacional de Estudos Populacionais, Caxambu/MG. Anais do X Encontro Nacional de Estudos Populacionais, v. 3. p. 741-770, 1996.

MAZIERO, V. P. P. O ensino superior privado em Pernambuco: um mapeamento do perfil dos dirigentes acadêmicos e sua relação com o desempenho institucional, Dissertação (Mestrado em Administração) - Universidade Federal de Pernambuco, CCSA, 2015.

OJIMA, R. Fronteiras Metropolitanas: Um Olhar a partir dos Movimentos Pendulares, Revista Paranaense de Desenvolvimento, Curitiba, n.121, p. 115-132, jul./dez, 2011.

OLIVEIRA. A. A, O cariri cearense: Da ocupação do território à institucionalização da Região metropolitana do Cariri. 2014. F. 138, Dissertação (Mestrado em Economia), UFRN, 2014.

OLIVEIRA, A. T. R. Dos Movimentos Populacionais à Pendularidade: Uma Revisão do Fenômeno Migratório no Brasil, In: XV Encontro Nacional de Estudos Populacionais, Caxambu, 2006.

PESSINI, D. S. As Metrópoles e seus Deslocamentos Populacionais Cotidianos: O Caso do Deslocamento Pendular na Região Metropolitana de Campinas, Dissertação (Mestrado em Demografia), UNICAMP, 2007.

QUEIROZ, S. N. Migração para o Ceará nos anos 90. Dissertação inédita (Mestrado em Economia), Universidade Federal da Paraíba, UFPB-CME, 2003.

ROCHA, D. M; DINIZ, F. R. Arenas de decisão, arranjos institucionais e reconfiguração sócio espacial ao sul da metrópole do Recife: o polo Suape no cerne das políticas de desenvolvimento de Pernambuco, Recife: Transformações na ordem urbana - organização Maria Ângela de Almeida Souza, Jan Biton ; coordenação Luiz Cesar de Queiroz Ribeiro. - 1. ed. - Rio de Janeiro : Letra Capital, p. 459-501, 2015.

SILVA, E. T. Estrutura e Mobilidade Espacial nas Metrópoles, Tese (Doutorado em Planejamento Urbano) em Planej. Urbano, 2012.

SILVA, J. G; QUEIROZ, S. N. Migração Interestadual para Região Metropolitana do Cariri (RMC). In: VII Congreso de la Asociación Latinoamericana de Población e XX Encontro Nacional de Estudos Populacionais, 2016, Foz do Iguaçu/ PR-Brasil. 2016.

, Mobilidade Pendular nas Regiões Metropolitanas do Nordeste (Fortaleza, Recife e Salvador). 2016, 97f. Monografia (Graduação em Economia). Universidade Regional do Cariri - URCA, Crato-CE, 2016. 